\title{
Influence of 6-aminonicotinamide (6AN) on Leishmania promastigotes evaluated by metabolomics: Beyond the pentose phosphate pathway
}

\author{
Shawgi Hago Almugadam ${ }^{\mathrm{a}, \mathrm{b}}$, Alessandro Trentini ${ }^{\mathrm{a}}$, Martina Maritati ${ }^{\mathrm{c}}$, Carlo Contini ${ }^{\mathrm{c}}$, \\ Gianluca Rugna ${ }^{\mathrm{d}}$, Tiziana Bellini ${ }^{\mathrm{a}}$, Maria Cristina Manfrinato ${ }^{\mathrm{a}}$, Franco Dallocchio ${ }^{\mathrm{a}}$, \\ Stefania Hanau ${ }^{\text {a,* }}$ \\ ${ }^{a}$ Medical Biochemistry, Molecular Biology and Genetics, Department of Biomedical and Specialty Surgical Sciences, Via Borsari 46, University of Ferrara, 44121, Ferrara, \\ Italy \\ ${ }^{\mathrm{b}}$ Present Address: Faculty of Medical Laboratory Sciences, University of Khartoum, P.O Box 321, Khartoum, 51111, Nile Avenue, Sudan \\ ${ }^{\mathrm{c}}$ Infectious Diseases and Dermatology, Department of Medical Sciences, Via Fossato di Mortara 64, University of Ferrara, 44121, Ferrara, Italy \\ d Modena Unit, Istituto Zooprofilattico Sperimentale della Lombardia e dell'Emilia-Romagna, Via Bianchi 9, 25124, Brescia, Italy
}

\section{A R T I C L E I N F O}

\section{Keywords:}

Leishmania

6-Aminonicotinamide

Metabolomics

Nicotinamidase

Pentose phosphate pathway

\begin{abstract}
A B S T R A C T
6-Aminonicotinamide (6AN) is an antimetabolite used to inhibit the NADPH-producing pentose phosphate pathway (PPP) in many cellular systems, making them more susceptible to oxidative stress. It is converted by a $\mathrm{NAD}(\mathrm{P})^{+}$glycohydrolase to 6-aminoNAD and 6-aminoNADP, causing the accumulation of PPP intermediates, due to their inability to participate in redox reactions. Some parasites like Plasmodium falciparum and Coccidia are highly sensitive but not all cell types showed a strong responsiveness to 6AN, probably due to the different targeted pathway. For instance, in bacteria the main target is the Preiss-Handler salvage pathway for NAD ${ }^{+}$ biosynthesis. We were interested in testing 6AN on the kinetoplastid protozoan Leishmania as another model to clarify the mechanisms of action of 6AN, by using metabolomics. Leishmania promastigotes, the life-cycle stage residing in the sandfly, demonstrated a three order of magnitude higher EC50 (mM) compared to $P$. falciparum and mammalian cells $(\mu \mathrm{M})$, although pre-treatment with $100 \mu \mathrm{M} 6 \mathrm{AN}$ prior to sub-lethal oxidative challenge induced a supra-additive cell kill in $L$. infantum. By metabolomics, we did not detect 6ANAD/P suggesting that $\mathrm{NAD}^{+}$glycohydrolases in Leishmania may not be highly efficient in catalysing transglycosidation as happens in other microorganisms. Contrariwise to the reported effect on 6AN-treated cancer cells, we did not detect 6phosphogluconate (6PG) accumulation, indicating that 6ANADP cannot bind with high affinity to the PPP enzyme 6PG dehydrogenase. By contrast, 6AN caused a profound phosphoribosylpyrophosphate (PRPP) decrease and nucleobases accumulation confirming that PPP is somehow affected. More importantly, we found a decrease in nicotinate production, evidencing the interference with the Preiss-Handler salvage pathway for $\mathrm{NAD}^{+}$biosynthesis, most probably by inhibiting the reaction catalysed by nicotinamidase. Therefore, our combined data from Leishmania strains, though confirming the interference with PPP, also showed that 6AN impairs the Preiss-Handler pathway, underlining the importance to develop compounds targeting this last route.
\end{abstract}

\section{Introduction}

6-aminonicotinamide (6AN) is a nicotinamide analogue (Fig. 1A) often used to inhibit the NADPH-producing pentose phosphate pathway (PPP) in many cellular systems, making the cells more susceptible to oxidative stress [1-5]. Indeed, co-treatment of cells with 6AN and either oxidants or redox-modulating drugs is able to decrease cell viability in several cell models $[1,4,6]$.

In particular, 6AN has been clinically used to treat advanced cancers not responsive to standard modes of therapy as well as in topical treatment of psoriasis [7-9], with its preferred use in combination with other chemotherapeutics increasing the effectiveness of the therapy [10-16]. The rationale for its combined use is generally to deplete cellular energy sources and to inhibit DNA synthesis and repair [17].

\footnotetext{
* Corresponding author. Department of Biomedical and Specialist Surgical Sciences, Section of Medical Biochemistry, Molecular Biology and Genetics, University of Ferrara, Via Luigi Borsari, 46, 44121, Ferrara, Italy.

E-mail addresses: shawgialmugadam@uofk.edu (S.H. Almugadam), trnlsn@unife.it (A. Trentini), martina.maritati@unife.it (M. Maritati), cnc@unife.it (C. Contini), gianluca.rugna@izsler.it (G. Rugna), blt@unife.it (T. Bellini), mmc@unife.it (M.C. Manfrinato), dlf@unife.it (F. Dallocchio), hns@unife.it (S. Hanau).
} 
A<smiles>NC(=O)c1ccc(N)nc1</smiles>

B

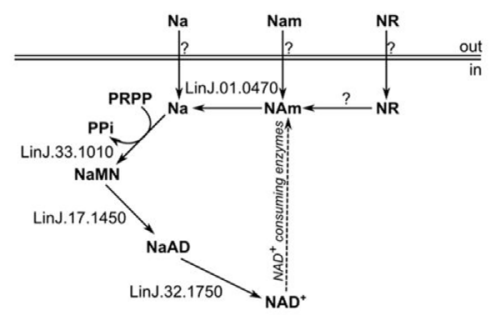

Fig. 1. A. The chemical structure of 6AN. B. The Preiss Handler pathway for $\mathrm{NAD}^{+}$synthesis in Leishmania. Abbreviations: NAm, nicotinamide, Na, nicotinic acid, NaMN, nicotinic acid mononucleotide, NaAD, Nicotinic acid adenine dinucleotide, NAD, Nicotinamide adenine dinucleotide, PRPP, 5phospho- $\alpha$-D-ribose 1-diphosphate, PPi, diphosphate (modified from Ref. [33]), enzymes gene names and accession numbers are indicated.

Once captured, in mammalian cells $6 \mathrm{AN}$ is converted to the not reducible 6-aminoNAD (6ANAD) and 6-aminoNADP (6ANADP) by a $\mathrm{NAD}(\mathrm{P})^{+}$glycohydrolase $[10,18,19]$, with the 6ANADP being a strong competitive inhibitor of the PPP dehydrogenases [20-23]. The inhibition of PPP dehydrogenases caused the accumulation of the PPP intermediate 6-phosphogluconate (6 PG) which in turn is able to inhibit the glycolytic enzyme phosphoglucose isomerase [24,25]. Seemingly, the same effects of the combination of 6AN with oxidants have also been observed in microorganisms such as Leishmania, highlighting the criticality of the PPP pathway for their survival during oxidative stress challenge [1].

Parasites of the genus Leishmania cause a group of diseases endemic in 98 countries with clinical manifestations ranging from self-healing cutaneous to destructive mucocutaneous and visceral forms, depending on the Leishmania species involved [26,27]. The parasite presents as polymorphic, existing in various forms including amastigotes, the mammalian phagocytic cell dwelling stage responsible for the pathology, and promastigotes, the life-cycle stage residing in the sandfly $[26,27]$.

Although the effect of 6AN on the PPP is well known and accepted, even in Leishmania, there are also cases where it seems not acting in the same way as in mammalian cells. An example comes from bacteria, whose glycohydrolases mediate NAD hydrolysis with the inability to catalyse the transglycosidation reaction needed to synthesize 6ANAD/P [28-31]. Data on 6AN-resistant mutants indicate that the mechanism of action of this antimetabolite on such cell models is the interference with the first two steps in the Preiss-Handler salvage pathway for NAD ${ }^{+}$ biosynthesis, through nicotinamidase (nicotinamide deamidase) and nicotinic acid phosphorybosyl transferase inhibition (Fig. 1B) [32] or feedback and expression regulating steps for these enzymes [34,35]. Therefore, not only the PPP but also the Preiss-Handler salvage pathway may be a possible target for the effect of 6AN on cell metabolism. Owing these premises and considering that $6 \mathrm{AN}$ has been always used in combination with other compounds, we were interested in studying the metabolic changes of the kinetoplastid protists Leishmania treated with 6AN through metabolomics approach. To the best of our knowledge, this is the first study probing the effects and modes of action of the sole molecule on Leishmania metabolism. The results we obtained highlighted a striking difference between some mammalian cell lines and these parasites, which showed a much lower sensitivity to 6AN due to different targeted metabolic pathways, which may represent the basis for novel strategies of action of antileishmanial drugs.

\section{Materials and methods}

\subsection{Materials}

All compounds were purchased from Sigma-Aldrich, GmbH, Germany. 6-Aminonicotinamide (6AN) was prepared in DMSO to the maximum concentration of 0.729 M. 6-Aminonicotinic acid (6ANa) was dissolved in either HOMEM or RPMI medium at $20 \mathrm{mM}$. Methylene blue (MB), malachite green (MG) and amphotericin B (AmB) were prepared in double distilled water at concentrations of $2.97 \mathrm{mM}, 10 \mathrm{mM}$ and $0.27 \mathrm{mM}$, respectively. All compounds were filter sterilized through $0.22 \mu \mathrm{m}$ filters.

\subsection{Parasites and cultures}

Three strains were used in this study, M379 Leishmania (L.) mexicana (MHOM/GT/2001/U1103), PCM5 L. infantum (MCAN/ES/98/ LIM-877) and IZSLER_MO1 L. infantum (from IZSLER in Modena, Italy) [36].

The promastigotes of the $L$. mexicana strain M379 and $L$. infantum strain PCM5 were routinely cultured in HOMEM medium (pH 7.2) [37] (GE Healthcare Bioscience, GmbH, Austria) supplemented with $10 \%$ heat inactivated foetal calf serum (HIFCS) (Gibco, Paisley, UK), $100 \mathrm{U} /$ $\mathrm{ml}$ Penicillin, and $100 \mathrm{U} / \mathrm{ml}$ Streptomycin sulphate in $25 \mathrm{~cm}^{2}$ nonvented flasks (Corning, USA) at $25^{\circ} \mathrm{C}$ in a humidified incubator under air as a gas phase. The promastigotes of the IZSLER_MO1 strain were cultured in RPMI 1640 medium supplemented with 15\% HIFCS and antibiotics as in HOMEM medium.

Axenic amastigotes of $L$. mexicana were prepared and continuously cultivated in Schneider's Drosophila Medium (SDM) (pH 5.5) supplemented with $20 \%$ HIFCS and $15 \mu \mathrm{g} / \mathrm{ml}$ hemin [38]. For the initiation of the amastigote cultivation, promastigotes were seeded in $25 \mathrm{~cm}^{2}$ vented tissue culture flasks (Corning, USA) at a density of $10^{6}$ cells $/ \mathrm{ml}$ and incubated at $32{ }^{\circ} \mathrm{C}$ in a humid incubator with $5 \% \mathrm{CO}_{2}$ for one week. The transformed amastigotes were passed through a 26-gauge syringe to break up the clumped cells before counting and routinely cultured under the same conditions and passaged in fresh medium once a week.

\subsection{Evaluation of the impairment of oxidative stress resistance}

After 6AN treatment both treated and control cells were diluted to $6 \times 10^{4}$ cells $/ \mathrm{mL}$ and challenged with $\mathrm{H}_{2} \mathrm{O}_{2}$ for $45 \mathrm{~min}$. Surviving parasites were counted microscopically using trypan blue staining and a hemocytometer. All values are reported as mean and SD. The comparisons of the percentage of living cells after treatment with 6AN and $\mathrm{H}_{2} \mathrm{O}_{2}$, alone or in combination, were performed by 1-way ANOVA followed by Bonferroni post-hoc test corrected for multiple comparison. All the analyses were carried out with GraphPad ${ }^{\circ}$ Prism 6 and a $\mathrm{p}<0.05$ was considered significant.

\subsection{Determination of 6-phosphogluconate dehydrogenase (6 PGD) activity}

After 6AN treatment both treated and control cells were washed twice with cold PBS and lysed by sonication of cell suspension in $50 \mathrm{mM}$ Tris, pH 7.5, $100 \mathrm{mM} \mathrm{NaCl}, 1 \%$ Triton X100, $5 \mathrm{mM}$ EDTA and other protease inhibitors. After centrifugation at $10,000 \mathrm{~g}$ at $4{ }^{\circ} \mathrm{C}$ the supernatant was added to $50 \mathrm{mM}$ Triethanolamine buffer, $\mathrm{pH} 7.5$ containing $0.1 \mathrm{mM}$ EDTA, $1.0 \mathrm{mM}$ 2-mercaptoethanol and $0.5 \mathrm{mM} \mathrm{NADP}^{+}$. After $10 \mathrm{~min} 1.45 \mathrm{mM} 6 \mathrm{PG}$ was added and 6 PGD activity was assayed at $340 \mathrm{~nm}$ for $40 \mathrm{~min}$ in a Tecan infinite 200 microplate reader and normalized for the cells number. Treatments were done in triplicate and in several independent experiments.

\subsection{Antileishmanial activity}

To find $\mathrm{EC}_{50}$ values against Leishmania growth, in 96-well flat- 
bottom polystyrene plates (Greiner Bio One Ltd) $15.6 \mathrm{mM}$ 6AN, $10 \mathrm{mM}$ 6ANA, $100 \mu \mathrm{M} \mathrm{MB}, 100 \mu \mathrm{M} \mathrm{MG}$, and $2 \mu \mathrm{M} \mathrm{AmB}$ were two-fold serially diluted 11 times in $100 \mu \mathrm{l}$ of complete culture medium/well. $100 \mu \mathrm{l}$ of parasite suspension was added to each well so the final parasite density in each well was either $10^{5}$ cells $/ \mathrm{ml}$ in some experiments or $10^{6}$ cells/ $\mathrm{ml}$ in others. The treated parasites were incubated for $72 \mathrm{~h}$ at $25^{\circ} \mathrm{C}$. The number of viable cells was then measured either using a hemocytometer, after fixing with $2 \%$ formaldehyde in phosphate buffered saline (PBS) $\mathrm{pH} 7.4$, or by Alamar Blue reduction, fluorescence measurement [39]. In the latter case $20 \mu \mathrm{l}(1 / 10$ th of the total volume in each well) of filter-sterilized Alamar Blue (SIGMA-ALDRICH CHEME, GmbH, Germany) was added to both treated and control cells in plates for fluorescence analysis. After $48 \mathrm{~h}$ incubation at $25^{\circ} \mathrm{C}$ the reaction was stopped by adding $50 \mu \mathrm{l}$ of $3 \%$ SDS in PBS (pH 7.4), in each well, for fluorescence measurement at $530 \mathrm{~nm}$ excitation and $590 \mathrm{~nm}$ emission wavelengths. Treatments were done in triplicate and in three independent experiments, the $\mathrm{EC}_{50}$ values were calculated using Prism 6.0 software nonlinear dose-response curve mode.

\subsection{Compound interaction analysis}

The modified fixed-ratio isobologram method was used to ascertain whether the mode action of the compounds is synergistic, indifferent or antagonistic $[40,41]$. The $\mathrm{EC}_{50}$ values of either 6-AN, MB or MG were determined first. The starting concentration of both MB and MG were 32 times their $\mathrm{EC}_{50}$ values. To avoid the effect of DMSO (solvent) on the parasites, 6AN was prepared at a concentration 4 times its $\mathrm{EC}_{50}$. Combinations ratios of 6AN:MB and MB:MG were 5:0, 4:1, 3:2, 2:3, 1:4 and 0:5. For each ratio, serial dilutions were made, and the $\mathrm{EC}_{50}$ values were calculated for each compound, then fractional inhibitory concentrations (FIC) were obtained dividing the $\mathrm{EC}_{50}$ values by the $\mathrm{EC}_{50}$ of the drug alone. The isobologram involved plotting one compound's FIC values against the other compound's FIC values. Each drug combination experiment was replicated three times.

\subsection{Microscopic analysis of L. mexicana promastigotes treated with $6 A N$}

Procyclic promastigotes were passaged daily for a week and then seeded at a density of $10^{5}$ cells $/ \mathrm{ml}$, in complete HOMEM medium with either $15.6 \mathrm{mM}$ 6AN or $2.14 \%$ DMSO alone, and in medium alone, as untreated control. Parasites were incubated at $25^{\circ} \mathrm{C}$ in a humidified incubator under air as a gas phase for $72 \mathrm{~h}$. Smears were prepared at a $0,6,14,48$, and $72 \mathrm{~h}$. Smears were fixed in methanol for $30 \mathrm{~s}$ and then stained for $10 \mathrm{~min}$ with $8 \%$ Giemsa stain (Fluka Analytical, SigmaAldrich, Germany) in Sörensen staining buffer. Slides were then washed with tap water, air dried, and examined under a light microscope $(100 \times$ magnification $)$

\subsection{Macrophage preparation and infection}

C57BL/6 mice (8-12 weeks old) were bred and housed under standard laboratory conditions at the University of Glasgow (Glasgow, Scotland). All experiments were performed under UK Home Office License. Mice were culled by a Schedule One method (exposure to carbon dioxide gas in a rising concentration) that is authorized by the Animals (Scientific Procedures) Act 1986. On day 0, bone marrow macrophages were prepared from the hind legs of male C57BL/6 mice aged between 8 and 12 weeks old under sterile conditions. Tibia and femur bones were cut at both ends and the bone marrow was flushed out into Petri dishes using a $5 \mathrm{ml}$ syringe and a 25-gauge needle filled with complete RPMI 1640 (RPMI supplemented with 1\% Penicillin/ Streptomycin and 10\% FBS, cRPMI) medium. Clumps were broken up by repeated aspiration of medium. The cell suspension was passed through a $70 \mu \mathrm{m}$ sterile cell strainer (Greiner Bio-One) into a $50 \mathrm{ml}$ falcon tube and then centrifuged at $300 \mathrm{~g}$ for $5 \mathrm{~min}$. The supernatant was discarded and the cells, suspended in $10 \mathrm{ml}$ cRPMI, counted and

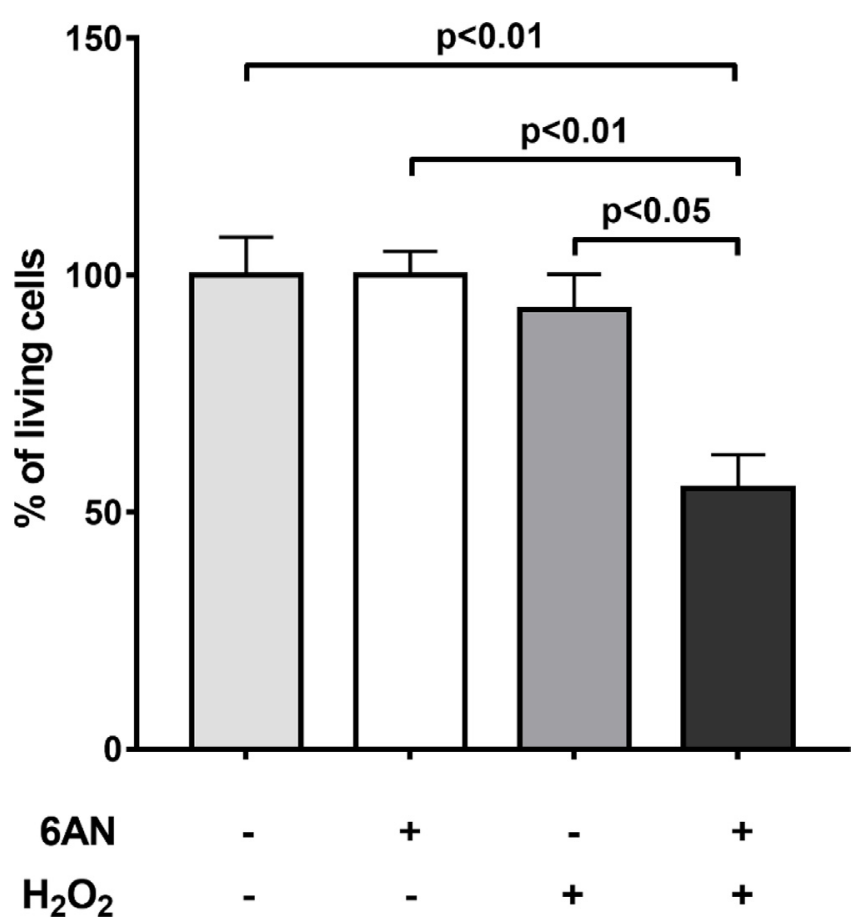

Fig. 2. The survival of canine Leishmania promastigotes exposed to $\mathrm{H}_{2} \mathrm{O}_{2}$ after $48 \mathrm{~h}$ of treatment with 6AN. The $Y$ axis presents the percentage of living cells. The parasites were exposed to $100 \mu \mathrm{M} \mathrm{H}_{2} \mathrm{O}_{2}$ for $45 \mathrm{~min}$ after $48 \mathrm{~h}$ of treatment with $100 \mu \mathrm{M} 6 \mathrm{AN}$. The average values of two experiments performed in duplicate \pm SD are given.
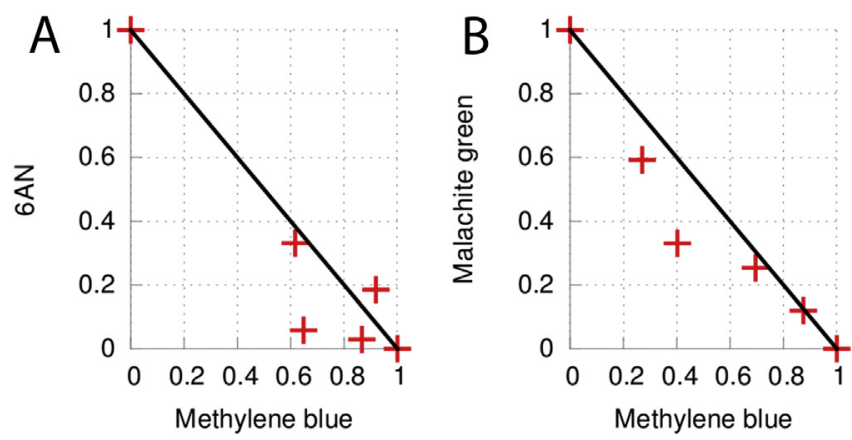

Fig. 3. Isobolograms of the interaction between 6AN/MB (A), and MB/MG (B) on L. mexicana promastigotes. In the axes the fractional inhibitory concentration (FIC) of 6-aminonicotinamide (6AN), methylene blue (MB) and malachite green (MG) are reported [40,41]. (For interpretation of the references to colour in this figure legend, the reader is referred to the Web version of this article.)

Table 1

Susceptibility of $L$. mexicana and $L$. infantum promastigotes to 6-aminonicotinamide (6AN), methylene blue (MB), malachite green (MG) and amphotericin $B$ (AmB).

\begin{tabular}{lll}
\hline Cell type & Compound & EC \\
\hline L. mexicana M379 & $6 \mathrm{AN}$ & $7.8 \pm 1.4 \mathrm{mM}$ \\
& MB & $2.8 \pm 1.6 \mu \mathrm{M}$ \\
& MG & $23.5 \pm 11.9 \mu \mathrm{M}$ \\
L. infantum PCM5 & AmB & $27 \pm 2.3 \mathrm{nM}$ \\
& $6 \mathrm{AN}$ & $4.3 \pm 1.34 \mathrm{mM}$ \\
L. infantum IZSLER_MO1 & AmB & $24 \pm 5.35 \mathrm{nM}$ \\
& $6 \mathrm{AN}$ & $1.8 \pm 0.36 \mathrm{mM}$ \\
\hline
\end{tabular}

Results are the means \pm SD of three independent experiments each performed in triplicate. 
resuspended at a density of $6-7 \times 10^{6}$ cells $/ \mathrm{ml}$. They were then plated in Petri dishes by adding $1 \mathrm{ml}$ of this suspension to a mixture of $2 \mathrm{ml}$ filtered L929 fibroblast supernatant and $7 \mathrm{ml}$ cRPMI, and incubated at $37^{\circ} \mathrm{C}, 5 \% \mathrm{CO}_{2}$. On day 3 , each Petri dish was supplemented with $5 \mathrm{ml}$ cRPMI and $2 \mathrm{ml}$ L929 supernatant. On day 6, the medium was removed and the Petri dishes were washed three times with warm cRPMI to remove non-adherent cells. $6 \mathrm{ml}$ ice cold PBS was added to each dish and left on ice for 1-2 min. Cells were scraped from the bottom of the dish, collected in a $50 \mathrm{ml}$ Falcon tube, spun for $5 \mathrm{~min}$ at $300 \mathrm{~g}$, and resuspended at a density of $10^{6}$ cells $/ \mathrm{ml}$ in warm cRPMI, then transferred to chamber slides (Lab-Tek ${ }^{\circ}$ Chamber Slide Products), 200 $\mu \mathrm{l} /$ well and incubated for $24 \mathrm{~h}$ at $32{ }^{\circ} \mathrm{C}$ and $5 \% \mathrm{CO}_{2}$ [42].

Procyclic L. mexicana promastigotes were seeded at $10^{5}$ cells $/ \mathrm{ml}$ and treated with $15.8 \mathrm{mM} 6 \mathrm{AN}$ in complete HOMEM medium in 12 well tissue culture plates for a time-course incubation; 7, 5, and 3 days, 24 and $8 \mathrm{~h}$. Parasites treated with $2.14 \%$ DMSO (the solvent used to dissolve 6AN) were used as controls. Before infection the parasites were washed twice with warm cRPMI, resuspended in cRPMI and counted. Macrophage/parasite, at a ratio of 1:4, were incubated in chamber slides, $24 \mathrm{~h}$ at $32^{\circ} \mathrm{C}, 5 \% \mathrm{CO}_{2}$. After washing three times with cRPMI was done and the macrophages were incubated for 5 days with daily washing and medium replacement. After 5 days, the medium was removed and cells washed with warm PBS, the plastic chambers were detached and slides were fixed while wet in absolute methanol, stained with $8 \%$ Giemsa and examined microscopically using the oil immersion lens $(100 \times$ magnification). This experiment was done in duplicate.

\subsection{Metabolite extraction}

Small molecule metabolites of Leishmania promastigotes were prepared for mass spectrometry analysis of the global metabolome according to the method of Creek et al. [43].

Promastigotes of either M379 L. mexicana or PCM 5 L. infantum were seeded at a density of $10^{6}$ cells $/ \mathrm{ml}$ in 8 non-vented $75 \mathrm{~mm}^{2}$ tissue culture flasks, each with a total volume of $20 \mathrm{ml}$. 6AN (in DMSO) was added to 4 flasks while DMSO alone was added to the other 4 flasks at the same percentage used with 6AN (1.07\%). After $24 \mathrm{~h}$ incubation at $25^{\circ} \mathrm{C}$ cells in each flask were counted and transferred at an equal density into a $50 \mathrm{ml}$ Falcon tube and then rapid quenching was carried out in a dry ice/ethanol bath. Tubes were spun down for $10 \mathrm{~min}$ at $1200 \mathrm{~g}$ at $4{ }^{\circ} \mathrm{C}$. The medium was aspirated and each pellet was suspended in $1 \mathrm{ml}$ ice cold PBS and transferred to Eppendorf tube. Tubes were centrifuged at $1200 \mathrm{~g}, 4^{\circ} \mathrm{C}$ for $5 \mathrm{~min}$, supernatants were removed and $200 \mu \mathrm{l}$ of extraction solvent (chloroform:methanol:water 1:3:1) were added to each tube, with a brief mixing. $500 \mu$ lof the extraction solvent, added to an empty tube, was used as a blank. Samples were shaken for $1 \mathrm{~h}$ at $4{ }^{\circ} \mathrm{C}$, centrifuged at $16,060 \mathrm{~g}, 4^{\circ} \mathrm{C}$ for $10 \mathrm{~min}$, and supernatants were swiftly transferred to labelled screw cap mass spectrometry vials. $40 \mu \mathrm{l}$ from each sample were pooled in a new vial and this was taken as the quality control (QC) sample. Finally, air was displaced from the top of the samples with argon gas and tubes were stored at $-80^{\circ} \mathrm{C}$.

\subsection{Hydrophobic interaction liquid chromatography-mass spectrometry (pHILIC-LC-MS)}

LC-MS analysis was performed on a Dionex UltiMate 3000 RSLC system (Thermo Fisher, Hemel Hempstead, UK) using a ZIC-pHILIC column (150 mm $\times 4.4 \mathrm{~mm}, 5 \mu \mathrm{m}$ column, Merck Sequant). L. mexicana and $L$. infantum samples, 6AN, DMSO, and QC were maintained at $4{ }^{\circ} \mathrm{C}$ prior use. $10 \mu \mathrm{l}$ sample were injected and the column was maintained at $30{ }^{\circ} \mathrm{C}$. Mobile phase A consisted of $20 \mathrm{mM}$ ammonium carbonate in water and $\mathrm{B}$ consisted of acetonitrile, flow rate was of $0.3 \mathrm{ml} / \mathrm{min}$. Gradient elution chromatography was performed starting with $20 \%$ solvent A. Within a 15 min time interval, solvent A was increased to $80 \%$ and solvent B decreased to $20 \%$, followed by an increase of A to

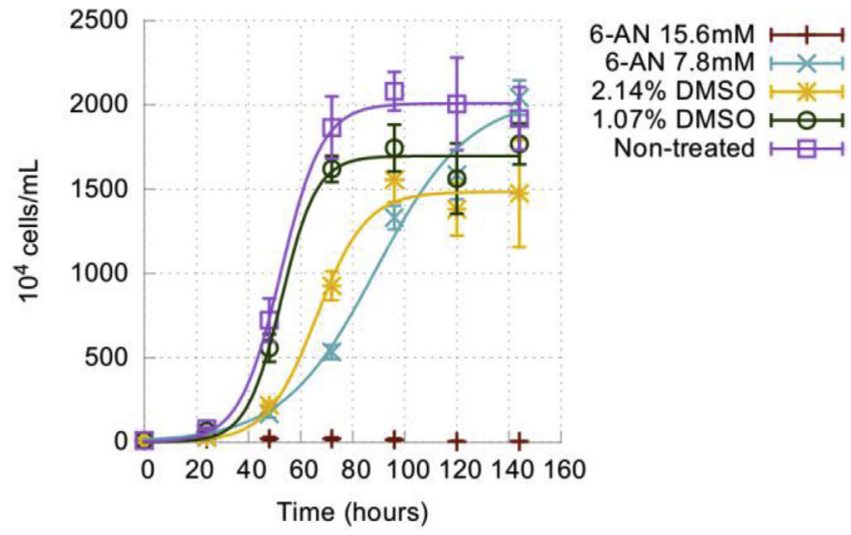

Fig. 4. 6AN treated $L$. mexicana promastigotes growth curve. The graphs are representative of three independent experiments. Each point is the mean and standard deviation of 4 replicates.

95\% and decrease of B to $5 \%$ within 15 min and maintained for $17 \mathrm{~min}$. Then the system returned to the initial solvent composition in $17 \mathrm{~min}$ and left to re-equilibrate under these conditions for $24 \mathrm{~min}$. For MS analysis of $L$. mexicana metabolites, a Thermo Orbitrap Q-Exactive mass spectrometer (Thermo Fisher Scientific, UK) was operated in polarity (positive and negative) switching mode and the MS settings were: resolution 50,000; AGC 106; $\mathrm{m} / \mathrm{z}$ range $70-1400$; sheath gas 40; auxiliary gas 5; sweep gas 1 ; probe temperature $150^{\circ} \mathrm{C}$; capillary temperature $275^{\circ} \mathrm{C}$. For $L$. infantum metabolites, an Orbitrap Fusion (Thermo Fisher Scientific) was operated in polarity switching mode and the MS settings were: resolution 120,000; AGC 200,000; $\mathrm{m} / \mathrm{z}$ range $70-1000$; sheath gas 40; auxiliary gas 5 ; sweep gas 1 ; probe temperature $150{ }^{\circ} \mathrm{C}$ and capillary temperature $325{ }^{\circ} \mathrm{C}$. For the positive mode ionisation: source voltage was $+4.3 \mathrm{kV}$ whereas, for the negative mode ionisation: source voltage was $-3.2 \mathrm{kV}$. S-Lens RF Level was $30.00 \%$. Prior to each analysis batch, mass calibration for each polarity were performed. Small metabolites calibration was done by the inclusion of low-mass contaminants in the standard (Thermo calmix masses). Electrospray ionisation was used for both positive and negative modes.

\subsection{Data processing pipeline}

For data analysis, IDEOMv18 (http://mzmatch.sourceforge.net/ ideom.php) was used [44]. Here raw files are converted to mzXML files and split polarity by proteowizard (msconvert) [45,46]. XCMS is then run to pick peaks and convert the files to PeakML format [47-49]. A key component of our data processing pipeline is the application of the default noise filters of mzMatch.R and IDEOM to obtain a list of monoisotopic peaks representing putative metabolites present in the label-free sample. After processing and deletion of noisy peaks, lipids, fatty acids and peptides (whose identifications are not reliable on this platform), 212 peaks were putatively identified by IDEOM (levels 2 and 3, MSI) in L. mexicana and 195 in L. infantum. A total of 54 metabolites were identified confidently in L. mexicana and 62 in $L$. infantum, by exact mass and retention time based on authentic metabolite standards (level 1 identification according to the Metabolomics Standards Initiative, MSI) [50]. Other identifications remain putative. Additional peaks within the rejected list may contain relevant information for later interpretation. Metabolomics data have been deposited to the EMBLEBI MetaboLights database (https://doi.org/10.1093/nar/gks1004. PubMed PMID: 23109552) with the identifier MTBLS443. The complete dataset can be accessed here http://www.ebi.ac.uk/metabolights/ MTBLS443 [51]. 


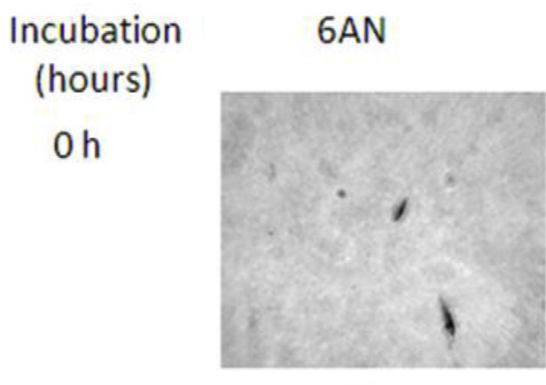

$6 \mathrm{~h}$
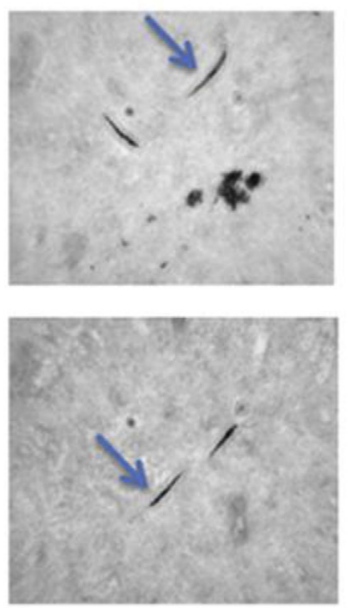

$14 \mathrm{~h}$

$48 \mathrm{~h}$
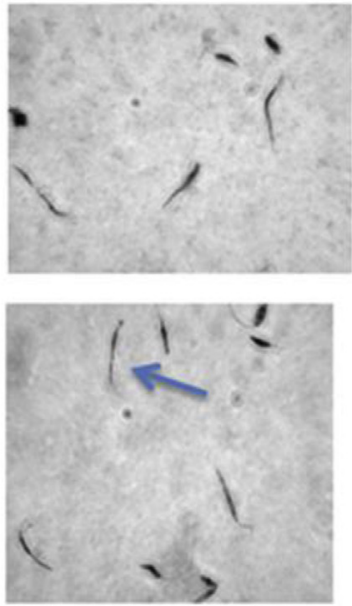

DMSO
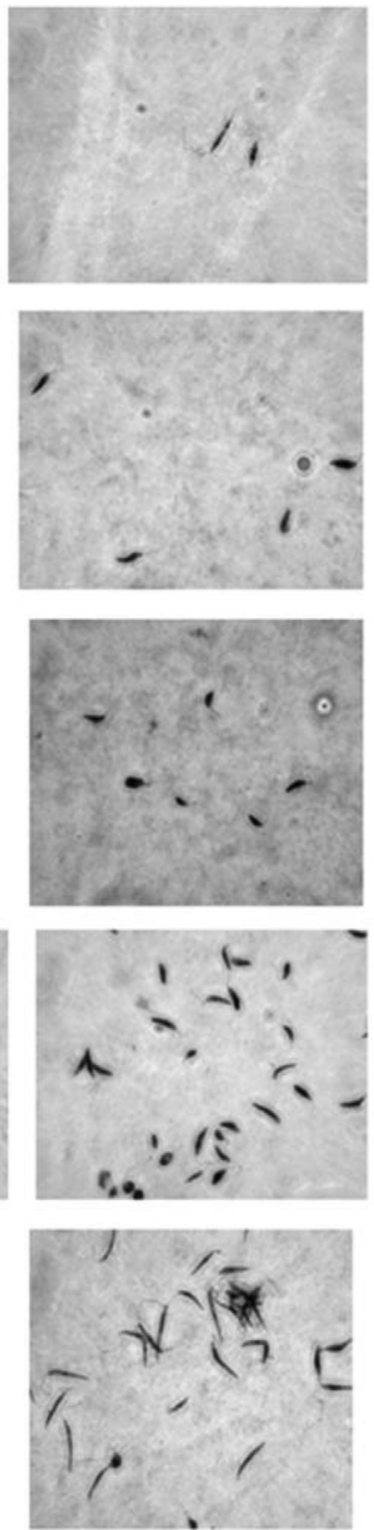

\section{Untreated}
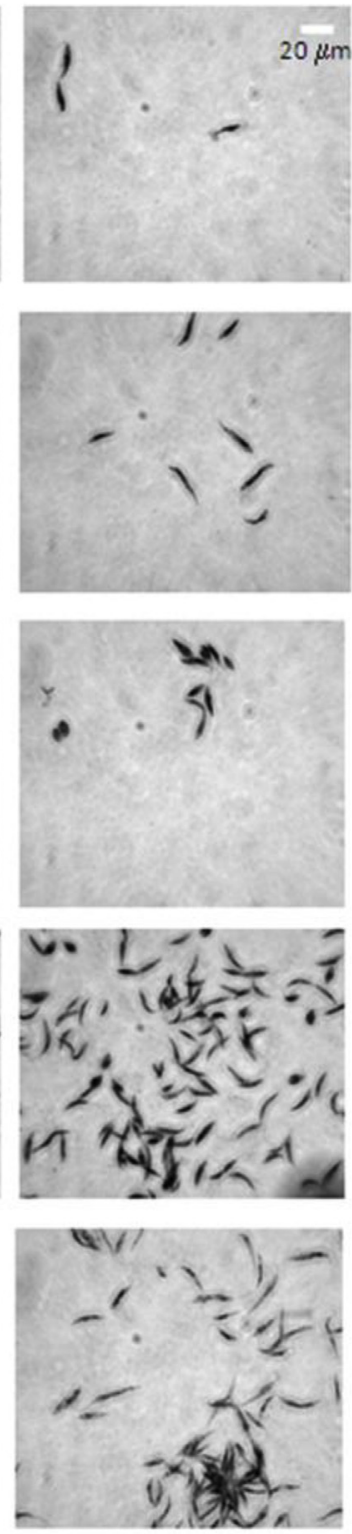

Fig. 5. General morphology of $L$. mexicana promastigotes treated with $15.6 \mathrm{mM}$ 6AN, $2.14 \%$ DMSO, and untreated controls. Arrows show elongated parasites. This experiment was replicated three times.

\subsection{Ethics statement}

Macrophages were isolated from mouse bone marrow under UK Home Office approval: Project licence PPL 60/4442, issued in compliance with The Animals (Scientific Procedures) Act 1986.

\section{Results and discussion}

\section{1. $6 A N$ and oxidative stress}

PPP being the main proposed target of 6AN [20-23], and a major provider of the coenzyme used in anti-oxidant reactions, NADPH, we first investigated whether 6AN treatment increased the susceptibility of Leishmania promastigotes to oxidative stress. To that end, canine $L$. infantum promastigotes treated for $48 \mathrm{~h}$ with $100 \mu \mathrm{M} 6 \mathrm{AN}$, were diluted and exposed to $100 \mu \mathrm{M} \mathrm{H}_{2} \mathrm{O}_{2}$ for $45 \mathrm{~min}$, after which parasites survival was determined by trypan blue staining and light microscopy. As evidenced by the results in Fig. 2, the treatment with 6AN had a negligible effect on the parasites survival ( $3 \%$, not significant). On the contrary Leishmania resistance to oxidative stress was indeed strongly impaired by $6 \mathrm{AN}$ treatment, since $\mathrm{H}_{2} \mathrm{O}_{2}$ reduced the control cells number only by $10 \%$ (not significant), whereas the cell viability after co-treatment with $6 \mathrm{AN}$ and $\mathrm{H}_{2} \mathrm{O}_{2}$ decreased by a further $40 \%$ (Fig. 2, $\mathrm{p}<0.05$ vs. $\mathrm{H}_{2} \mathrm{O}_{2}$ ).

We also determined whether 6AN action was synergistic with stress inducing agents such as methylene blue and malachite green. By the fixed-ratio isobologram method [40,41], it is possible to identify if the effect of two compounds is additive, when the total fractional maximum effect line (TFME, reciprocal position of the FIC, fractional inhibitory effect, of the two compounds) is a diagonal line connecting the two coordinates $(0 ; 1$ and $1 ; 0)$ or it is antagonistic (convex apparent TFME line, that is the points are above the diagonal) or synergistic (concave apparent TFME line, that is the points are distributed below the line). In Fig. 3 representative isobolograms are reported for 6AN/MB and MG/ 


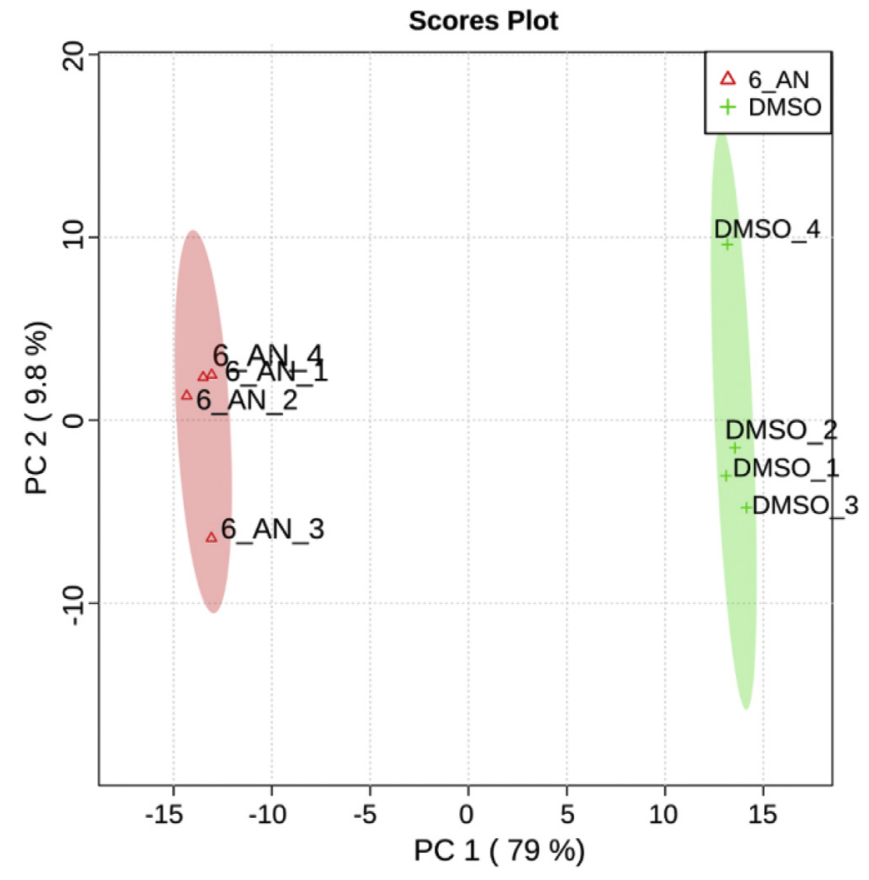

Fig. 6. Principal Component Analysis of 6AN and DMSO treated L. mexicana samples. 6AN and DMSO data were uploaded to Metaboanalyst, log transformed prior to Principal Component Analysis (PCA). The coloured areas denote the $95 \%$ confidence interval.

MB combinations against $L$. mexicana promastigotes. From these results, we cannot confidently state that the two dyes MG and MB are synergistic; in addition, our data cannot clearly indicate synergy or antagonism for $6 \mathrm{AN}$ and $\mathrm{MB}$ too, although the points clustered at the extremities of the axes. Thus we cannot also exclude an additive effect. Actually, these dyes have a complex action mechanism involving multiple targets, since both are able to bind DNA and many other biomolecules [52-56] as well as may present protective effects against oxidant species $[52,57,58]$.

\subsection{AN treatment caused a leishmaniostatic effect}

The activity of 6AN on Leishmania viability was tested as stated in the material and methods section and the results are reported in Table 1.

As evidenced, L. mexicana showed a higher $\mathrm{EC}_{50}(7.8 \mathrm{mM})$ compared with more effective compounds such as MB $(2.8 \mu \mathrm{M})$, MG $(23.5 \mu \mathrm{M})$ and $\mathrm{AmB}(27 \mathrm{nM})$, in agreement with previous results showing a lack of influence of a 6AN treatment $(5 \mathrm{mM})$ for short times $(12 \mathrm{~h})$ on $L$. donovani cell viability [1]. On the contrary, the axenic amastigotes of $L$. mexicana were even more resistant to 6AN than its promastigotes, making thus impossible for us to calculate the $\mathrm{EC}_{50}$. On the other hand, the effect of 6AN on promastigotes from other tested Leishmania strains seemed different, evidencing an increased sensitivity relative to the compound. Indeed, promastigotes of the PCM5 and the IZLER_MO1 $L$. infantum strains showed a lower $\mathrm{EC}_{50}$ value of $4.3 \mathrm{mM}$ and $1.8 \mathrm{mM}$, respectively, compared to L. mexicana (Table 1 ). As a comparison, 6AN is able to inhibit the growth of human embryonic palatal mesenchymal cells with an $\mathrm{EC}_{50}$ of $27 \mu \mathrm{M}$ [59] and intraerythrocytic stages of Plasmodium falciparum at $\mathrm{EC}_{50}$ of $10 \mu \mathrm{M}$ [60], indicating that 6AN was acting differently against Leishmania and these other cell types.

By contrast, the treatment of IZSLER_MO1 L. infantum strain with the precursor 6-aminonicotinic acid (6ANa) did not show any substantial effect even at high concentration $(10 \mathrm{mM}$, data not shown).

Previous reports showed that nicotinamide inhibits Leishmania
$\mathrm{NAD}^{+}$-dependent deacetylase activity (the silent information regulator protein, sirtuin, SIR2) at millimolar concentration [61] whereas 6AN can inhibit the human lymphocytes sirtuin poly (ADP-ribose) polymerase activity at $2 \mathrm{mM}$ concentration [17]. Leishmania SIR2 was shown to have an important role in the survival and virulence of amastigotes, as well as in the survival of promastigotes only under starvation conditions with glucose as a unique source of energy [62,63]. However, since amastigotes were not affected by 6AN in our experimental setup and previous reports showed a selective inhibition of amastigotes growth compared to promastigotes [61], it is unlikely for this enzyme to be a target of 6AN in Leishmania.

Then, we tested whether the observed effect of 6AN on Leishmania proliferation could be explained as a cytostatic activity. To this end, cells were incubated with 6AN at the calculated EC50 for different timepoints (from 0 to $140 \mathrm{~h}$ ) and the cell number, expressing the growth of the cells, was evaluated by a hemocytometer. As summarized in Fig. 4, 6AN showed a leishmaniostatic action where parasites treated with $7.8 \mathrm{mM}$ 6AN (Fig. 4, cyan lines) grew very slowly compared to the controls (Fig. 4, DMSO-treated, green and yellow lines, and untreated controls, violet line). However, they regained their growth after 2 days of incubation. Parasites treated with $15.6 \mathrm{mM} 6 \mathrm{AN}$, corresponding to the $\mathrm{EC}_{100}$, did not grow and showed soon a marked morphology change (see below).

The leishmaniostatic effect was also evident by microscopic analysis of $L$. mexicana promastigotes treated with $15.6 \mathrm{mM}$ 6AN (Fig. 5). Smears of $6 \mathrm{AN}$-treated procyclic promastigotes were prepared at 0,6 , 14, 48, and $72 \mathrm{~h}$ time points. After just $6 \mathrm{~h}$ of incubation, the cells showed an unusual body elongation (Fig. 5, arrows; observed in about $50 \%$ of the cells) while the control became long slender nectomonads (late logarithmic forms) after 48-72 h of incubation (late logarithmic forms) (Fig. 5). The elongated morphology observed whenever the parasite cultures were treated with 6AN, was also shown during purine starvation [64], in agreement with the metabolomics results presented below.

Promastigotes treated with $15.6 \mathrm{mM}$ 6AN for different times, were used to infect mouse bone marrow derived macrophages. Infectivity to macrophages of all treated parasites was similar to that of the control cells (data not shown).

\subsection{Metabolomics profile}

Given the large difference in sensitivity to 6AN between Leishmania and mammalian cells, studying changes in the parasite metabolome due to 6AN treatment can highlight important differences between the parasite and mammalian host biochemistry that might be exploited for drug target research.

Metabolomics analysis was performed on the extracted metabolites of $L$. mexicana strain M379 and $L$. infantum strain PCM5 promastigotes treated for $24 \mathrm{~h}$ with $7.8 \mathrm{mM}\left(\mathrm{EC}_{50}\right)$ and $8.6 \mathrm{mM}\left(2 \times \mathrm{EC}_{50}\right) 6 \mathrm{AN}$, respectively. This incubation time and the starting cell density (see Methods), were chosen in order to extract the metabolites before the 6AN-treated cells die or the DMSO-treated control cells enter the stationary phase (about $72 \mathrm{~h}$ ).

Mass spectral raw data were processed using IDEOM [51] then filtered manually (see Methods). The filtered file was then uploaded to MetaboAnalyst 3.0 [65] to calculate $p$ values via $t$-tests and calculate the false detection rates (FDR) using Benjamini-Hochberg correction after having log transformed the data. Any putatively identified metabolite that does not pass the $t$-test was excluded from the analysis (FDR $<0.05$ ). The final lists of significant metabolites are available as supplementary S1 and S2 Tables.

As evidenced by principal component analysis (PCA, Fig. 6), the 6AN and DMSO treated groups were clearly separated with 6AN present only in samples of promastigotes treated with 6AN as expected (see S1 table). A clear-cut separation is also evident from the heat map of the main metabolites that showed differences between 6AN and DMSO 


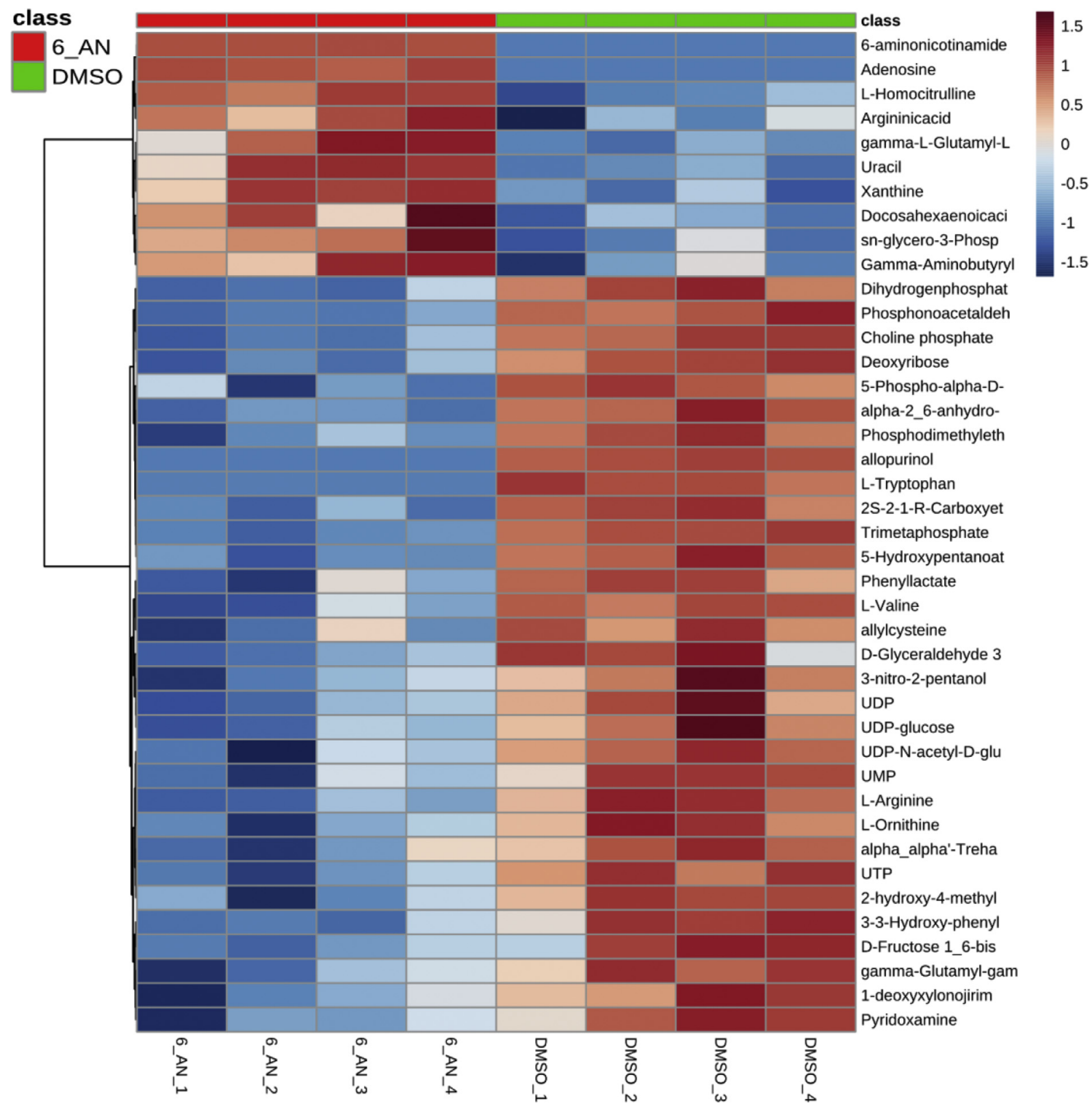

Fig. 7. Heat-map of the major metabolites that differ between 6AN treated and control DMSO-treated, L. mexicana promastigotes. The average of results from four experiments are reported. Relative metabolite abundance is depicted by red bars, while relative metabolite lack by blue bars. (For interpretation of the references to colour in this figure legend, the reader is referred to the Web version of this article.)
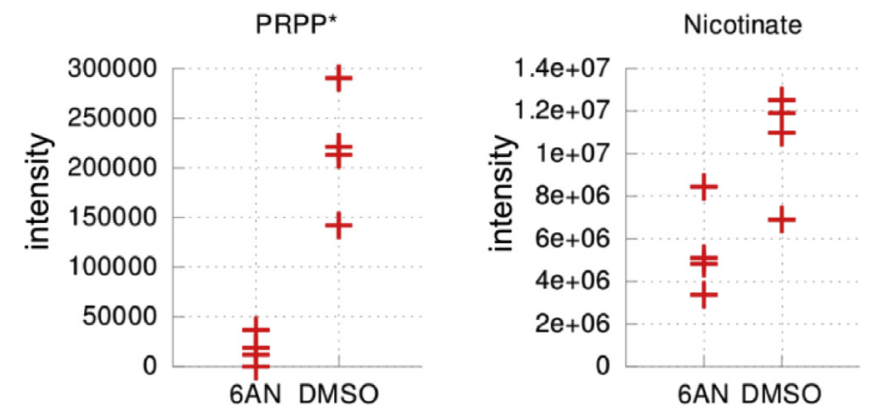

Fig. 8. PRPP and Nicotinate intensities in 6AN treated cells and DMSO controls. *: FDR $<0.05$. treated L. mexicana promastigotes (Fig. 7).

Glutathione and 6-phosphogluconate (6 PG) levels were similar to those of the controls and other downstream intermediates of carbohydrate metabolism from the PPP were unchanged, suggesting that Leishmania cells respond differently to 6AN than mammalian cells where the accumulation of 6 PG leading to secondary glycolysis inhibition has been reported $[10,66]$.

From our data, 6AN caused a very marked depletion in the intermediate of carbohydrate metabolism 5-phospho- $\alpha$-D-ribose 1-diphosphate (PRPP) and a small (almost significant, FDR $=0.09$ ) decrease in nicotinate (nicotinic acid, Na) (Fig. 8 and S1 Table), which was more evident and significant in 6AN-treated $L$. infantum promastigotes (S2 Table). Unfortunately, PRPP was not visible in this dataset for unknown reasons. In addition, we could not detect the NAD and NADP derivative of 6AN. It is possible that they were not produced in the parasites, although we cannot rule out that they were not detected using the employed LC-MS platform. 
$\mathrm{UMP}^{*}$

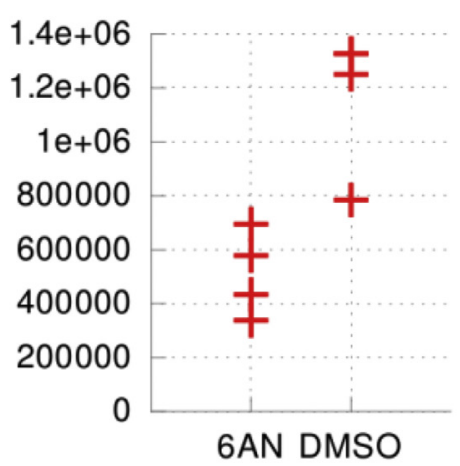

UDP-glucose*

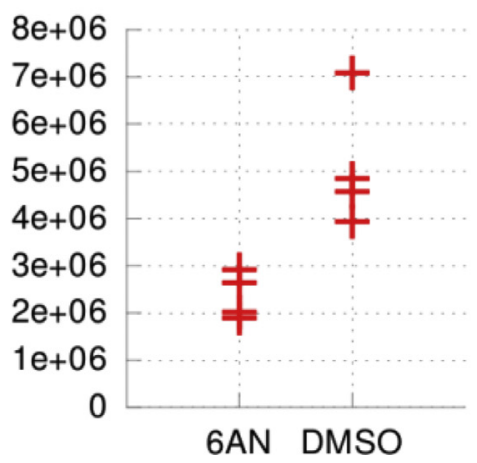

UDP*

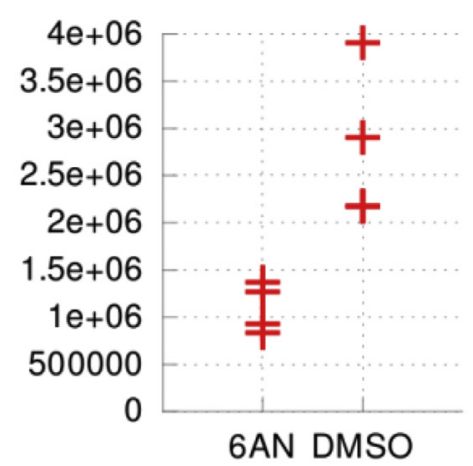

UTP* $^{*}$

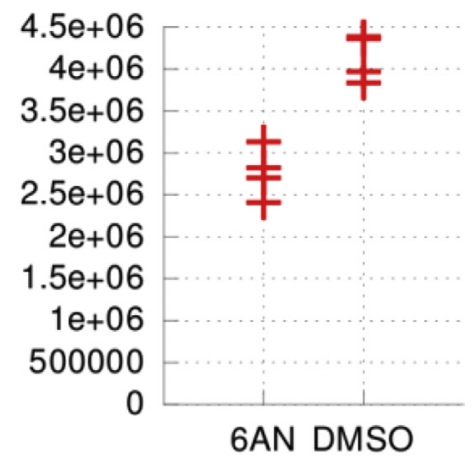

Fig. 9. Reduced levels of nucleotides, and their carbohydrate derivatives in 6AN treated cells, compared to DMSO controls.
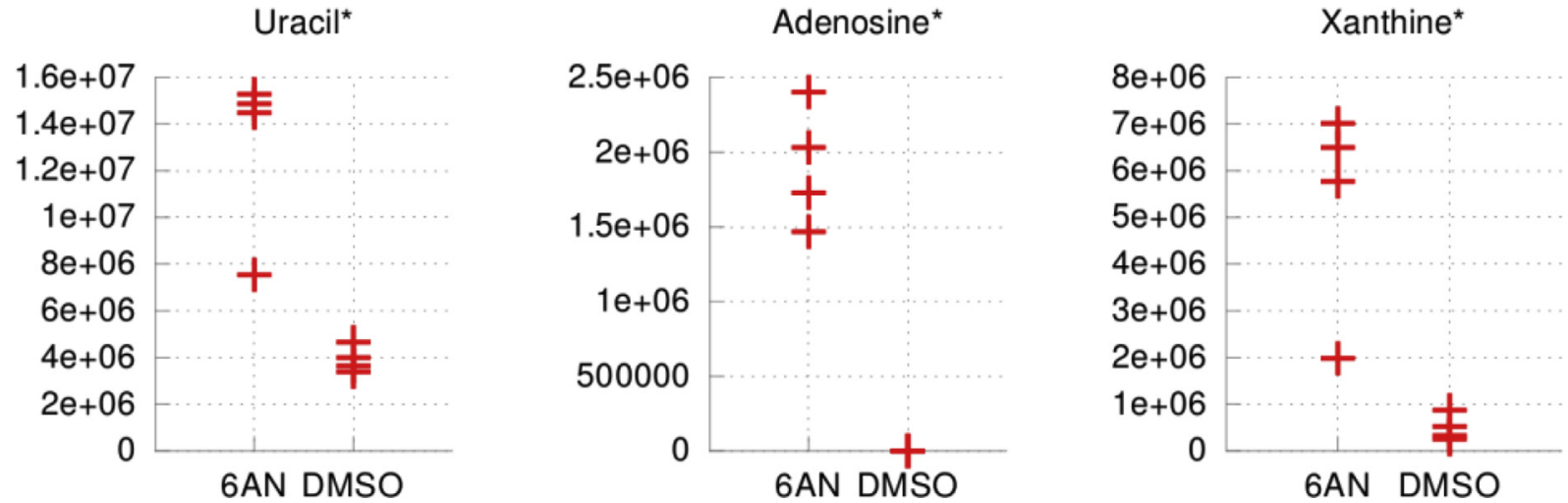

Fig. 10. Increased pyrimidine precursors and salvaged purine precursors moieties in 6AN treated cells compared to DMSO controls.

The observed decrease in PRPP when cells were treated with 6AN may be partially due to the interaction of 6AN with this molecule, for instance by forming glycosidic bonds through enzymatic reaction. However, the resultant adduction product was not visible in mass spectra thus we cannot exclude or confirm this hypothesis. Therefore, the PRPP decrease could result from the perturbation of the PPP. Indeed, PRPP is synthesized from ribose 5-phosphate which in turn can be produced either in the PPP or by direct uptake and phosphorylation from the culture medium or through degradation of nucleosides [67-69]. The large increase in sensitivity to oxidative stress of $L$. infantum when treated with 6AN suggests that PPP is in some way troubled. Consistently, the activity of the PPP enzyme 6-phosphogluconate dehydrogenase (6 PGD) was found reduced in the lysate of $L$. infantum promastigotes treated for $48 \mathrm{~h}$ with $200 \mu \mathrm{M}$ 6AN, compared to untreated cells $\left(1.2 \pm 0.202 \cdot 10^{-7} \mathrm{nmol} \cdot \mathrm{min}^{-1}\right.$ cell $^{-1}$ compared to $2.9 \pm 0.202 \cdot 10^{-7} \mathrm{nmol} \cdot \mathrm{min}^{-1} \mathrm{cell}^{-1}$, data not shown). Furthermore, a significant decrease in NADPH and the PPP intermediate D- sedoheptulose 7-phosphate levels were found in 6AN-treated L. infantum promastigotes (S2 Table). Therefore, we hypothesize that this PPP perturbation is ultimately reflected in the decreased PRPP levels we found, which then can induce a status of cell stasis.

Supporting this hypothesis, the addition of ribose to the culture medium improved the growth of 6AN-treated L. mexicana promastigotes by $50 \%$ compared to those cultured in a medium containing glucose alone (data not shown).

In addition to the perturbed PPP, 6AN seems to induce disturbance also in the Preiss-Handler pathway. Leishmania synthesises NAD $^{+}$from nicotinic acid (Na), which is a precursor in the Preiss-Handler salvage pathway for $\mathrm{NAD}^{+}$biosynthesis, deriving from nicotinamide (NAm) through the catalytic activity of nicotinamidase (Fig. 1B, reaction catalysed by LinJ.01.0470). Na then combines with PRPP to generate Na mononucleotide (NaMN) in the reaction catalysed by Na phosphoribosyltransferase. NaMN is then converted to NaAD by NaMN adenylyltransferase, and NaAD to $\mathrm{NAD}^{+}$by an ammonia-dependent $\mathrm{NAD}^{+}$ 


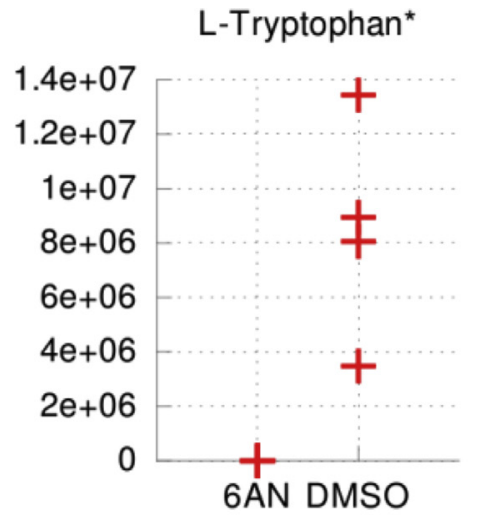

L-Ornithine*

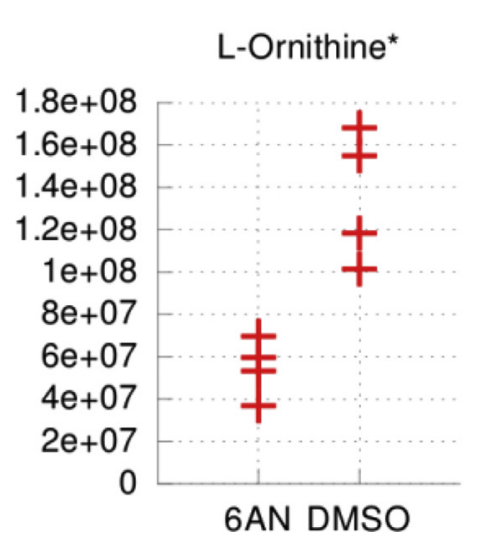

L-Arginine*

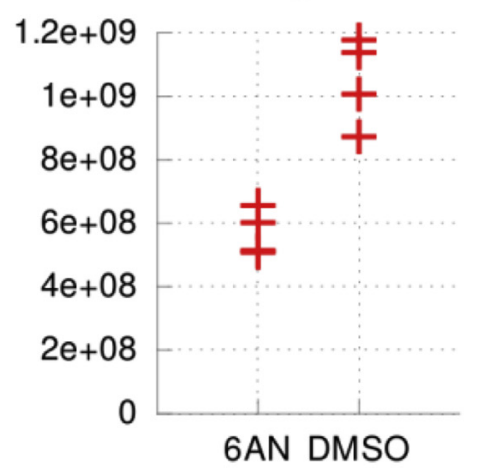

Argininic acid*

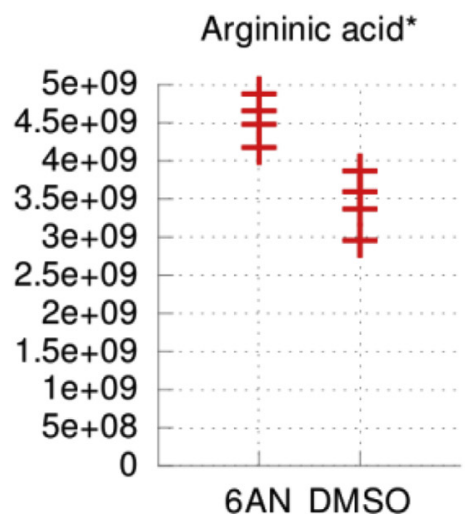

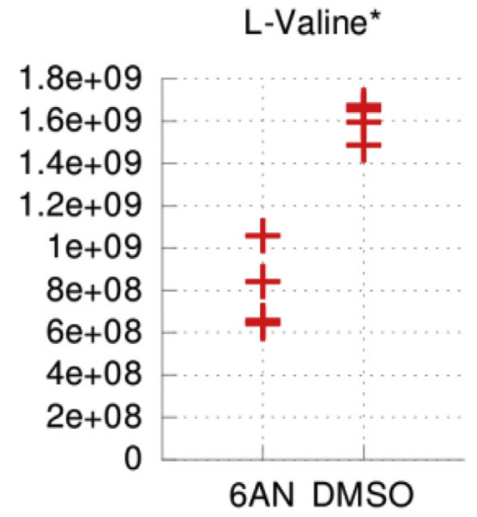

Fig. 11. Reduced levels of L-tryptophan, L-arginine, L-valine, L-ornithine and increased level of argininic acid in L. mexicana promastigotes treated with 6AN.

synthase (Fig. 1B) [33]. The nicotinate drop suggests that a primary target of 6AN might be nicotinamidase, whose inhibition should cause a consequent decrease in all the following reactions of the Preiss-Handler pathway, in fact $\mathrm{NAD}^{+}$was significantly decreased in 6AN-treated $L$. infantum promastigotes (S2 Table). The lack of effect of 6-aminonicotinic acid we found on $L$. infantum promastigotes is in agreement with nicotinamidase inhibition, pointing to the already suggested essential role of this enzyme in Leishmania [33,70].

PRPP is also used in the purine and pyrimidine nucleotide syntheses. Leishmania lacks the de novo purine biosynthetic pathway depending exclusively on salvage pathway while both de novo and salvage pathways exist for pyrimidine synthesis [71]. Consistently, nucleotides (UMP, UDP, UTP) and nucleotide derivatives such as UDP-glucose and UDP-N-acetyl-D-glucosamine showed a lower abundance in the 6ANtreated parasites than in the DMSO-treated control (Figs. 7 and 9). By contrast, their purine and pyrimidine precursors (xanthine and uracil) accumulated (Figs. 7 and 10). Thus, a loss of PRPP (due to both depression of its synthesis and its exacerbated consumption) perturbed nucleotide metabolism, preventing the creation of nucleotides while the cognate nucleobases accumulate. The same effect is generated when a defect in the synthesis of $\mathrm{NAD}^{+}$occurs, shown by Na decrease, and $\mathrm{NAD}^{+}$decline in $L$. infantum (S2 Table), impairing all NAD/H requiring reactions, like IMP dehydrogenase involved in purine nucleotides synthesis (IMP is transformed into xanthosine monophosphate (XMP), which is then converted to GMP by GMP synthetase). In agreement with our results, it has been reported that the lack of $\mathrm{NAD}(\mathrm{P})^{+}$induces stasis, rather than death, in most cells [72]. Interestingly, we found that adenosine was increased in 6AN-treated cells indicating that this metabolite may have a different origin (e.g. enhanced transport from the medium in response to falling levels of internal nucleoside) (Figs. 7 and 10). In L. mexicana, salvaged adenosine is either directly metabolized to AMP by the action of adenosine kinase (AK), or converted to inosine and then to hypoxanthine, whereas in L. donovani, adenosine is preferentially transformed to adenine [73,74]. In $L$. infantum the metabolism of adenosine is probably similar to that of $L$. donovani given the phylogenetic proximity and genetic similarity of these species, and therefore the possibility by $L$. mexicana to bypass PRPP requirement in adenosine metabolism might partially explain why it seemed slightly less sensitive to 6AN than $L$. infantum.

Other significant changes caused by the treatment with 6AN were in amino acids including L-tryptophan, L-valine and L-arginine which were decreased in 6AN-treated parasites, and metabolites related to arginine like L-ornithine, which was decreased, while argininic acid, a compound produced from arginine [75], increased (Figs. 7 and 11). This metabolite formed via deamination of arginine (the substrate for inducible nitric oxide synthase, NOS, in macrophages) is supposed to be produced by the parasites as a mechanism of evasion of host cells immunity [75]. In this case, the increased argininic acid could be a response against drug perturbation.

\section{Conclusions}

From our data we can hypothesize a two-folded action of 6AN on Leishmania metabolism: on one side, 6AN may perturb the PPP by inducing a decrease in ribose and PRPP production as well as in other intermediates of the pathway, ultimately leading to a decreased abundance of nucleotides and $\mathrm{NAD}^{+}$. This gross perturbation has never been reported in these cells, and the most frequent observed metabolic effect of 6AN has been the accumulation of 6 PG obtained in other cell models [66]. Thus, since we did not find an increase in 6 PG as previously reported in cancer cells, it seems that the inhibition of 6 PG dehydrogenase (6 PGD) by 6ANADP is not the main 6AN effect in Leishmania. In agreement, significant differences were found between the human and the kinetoplastid enzyme [76-80]. Furthermore, since the $6 \mathrm{ANAD} / \mathrm{P}$ were not found, it can be deduced that the glycohydrolases that catalyse transglycosidation and produce $6 \mathrm{ANAD} / \mathrm{P}$ from $6 \mathrm{AN}$ are 
not so active in Leishmania, as well as in other microorganisms [28-31] and they probably possess $\beta-\mathrm{NAD}^{+}$glycohydrolases of a different type. Of note, in bacteria, small 6ANAD/P amounts are synthesized in the parasite Preiss-Handler NAD ${ }^{+}$biosynthesis salvage pathway [34].

On the other side, the most intriguing effect of 6AN on Leishmania is the disruption of the Preiss-Handler salvage pathway for the synthesis of $\mathrm{NAD}^{+}$. Indeed, the prevailing data we obtained suggest that the most likely biochemical target of $6 \mathrm{AN}$ is the nicotinamidase, catalysing the production of nicotinate from nicotinamide thus affecting all the following reactions. This is of paramount importance considering that Leishmania lacks the de novo synthesis pathway for $\mathrm{NAD}^{+}$and totally depends on the Preiss-Handler pathway for its supplementation [33], confirming the importance of $\mathrm{NAD}^{+}$homeostasis and of this pathway in Leishmania biology. Therefore, our study suggests that, although with limitations, 6AN could be a good starting point for the further design of more specific and effective inhibitors against nicotinamidase as therapeutic target for the treatment of such a challenging disease.

\section{Acknowledgements}

SHA was supported by Research Mobility Grants from Ferrara University; SH, TB, FD, AT, CC and MM were supported by Ferrara University. Some infrastructures used in this project were in the Wellcome Centre for Molecular Parasitology, Institute of Infection, Immunity and Inflammation, University of Glasgow and Glasgow Polyomics, UK. We wish to express gratitude to Michael P. Barrett, Fiona Achcar, Kevin Rattigan of the Institute of Infection, Immunity and Inflammation, University of Glasgow and all the staff of Glasgow Polyomics for their advice and expert technical assistance. The work contained in this manuscript is component of the $\mathrm{PhD}$ dissertation of SHA.

\section{Appendix A. Supplementary data}

Supplementary data related to this article can be found at https:// doi.org/10.1016/j.cbi.2018.08.014.

\section{Transparency document}

Transparency document related to this article can be found online at https://doi.org/10.1016/j.cbi.2018.08.014.

\section{References}

1] A.K. Ghosh, A.H. Sardar, A. Mandal, S. Saini, K. Abhishek, A. Kumar, B. Pukait, R. Singh, S. Das, R. Mukhopadhyay, S. Roy, P. Das, Metabolic reconfiguration of the central glucose metabolism: a crucial strategy of Leishmania donovani for its survival during oxidative stress, Faseb. J. 29 (2015) 2081-2098.

[2] J.S. Hothersall, M. Gordge, A.A. Noronha-Dutra, Inhibition of NADPH supply by 6 aminonicotinamide: effect on glutathione, nitric oxide and superoxide in J774 cells, FEBS Lett. 434 (1998) 97-100.

[3] F. Rolfs, A. Kuehme, S. Kramer, E. Haertel, S. Muzumdar, J. Wagner, Y. Tanner, F. Bohm, S. Smola, N. Zamboni, M.P. Levesque, et al., Nrf2 activation promotes keratinocyte survival during early skin carcinogenesis via metabolic alterations, Canc. Res. 75 (2015) 4817-4829.

[4] A.A. Parkhitko, C. Priolo, J.L. Coloff, J. Yun, J.J. Wu, K. Mizumura, I.A. Malinowska, J. Yu, D.J. Kwiatkowski, J.W. Locasale, J.M. Asara, A.M. Choi, T. Finkel, E.P. Henske, Autophagy-dependent metabolic reprogramming sensitizes TSC2-deficient cells to the antimetabolite 6-aminonicotinamide, Mol. Canc. Res. 12 (2014) 48-57.

[5] E. Tsouko, A.S. Khan, M.A. White, J.J. Han, Y. Shi, F.A. Merchant, M.A. Sharpe, L. Xin, D.E. Frigo, Regulation of the pentose phosphate pathway by an androgenreceptor-mTOR-mediated mechanism and its role in prostate cancer cell growth, Oncogenesis 3 (2014) e103, https://doi.org/10.1038/oncsis.2014.18.

[6] R. Venè, B. Cardinali, G. Arena, N. Ferrari, R. Benelli, S. Minghelli, A. Poggi, D.M. Noonan, A. Albini, F. Tosetti, Glycogen synthase kinase 3 regulates cell death and sutvival signalling in tumor cells under redox stress, Neoplasia 16 (2014) $710-722$.

[7] C.P. Perlia, S. Kofman, H. Sky-Peck, S.G. Taylor, Clinical use of 6-aminonicotinamide in patients with disseminated neoplastic disease, Cancer 14 (3) (1961) 644-648.

[8] F.P. Herter, S.G. Weissman, H.G. Thompson, G. Hyman, D.S. Martin, Clinical experience with 6-aminonicotinamide, Canc. Res. 21 (1961) 31-37.

[9] H.S. Zackheim, Topical 6-aminonicotinamide plus oral niacinamide therapy for psoriasis, Arch. Dermatol. 114 (11) (1978) 1632-1638.

[10] J.C. Street, U. Mahmood, D. Ballon, A.A. Alfieri, J.A. Koutcher, ${ }^{13} \mathrm{C}$ and ${ }^{31} \mathrm{P}$ NMR investigation of effect of 6-aminonicotinamide on metabolism of RIF-1 tumor Cells in Vitro, J. Biol. Chem. 271 (8) (1996) 4113-4119.

[11] D.M. Shapiro, L.S. Dietrich, M.E. Shils, Quantitative biochemical differences between tumor and host as a basis for cancer chemotherapy, Canc. Res. 17 (1957) 600-604

[12] D.L. Walker, J.M. Reid, P.A. Svingen, R. Rios, J.M. Covey, M.C. Alley, M.G. Hollingshead, Budihardjo II, S. Eckdahl, S.A. Boerner, S.H. Kaufmann, M.M. Ames, Murine pharmacokinetics of 6-aminonicotinamide (NSC 21206), a novel biochemical modulating agent, Biochem. Pharmacol. 58 (1999) 1057-1066.

[13] Budihardjo II, S.A. Boerner, S. Eckdahl, P.A. Svingen, R. Rios, M.M. Ames, S.H. Kaufmann, Effect of 6-aminonicotinamide and other protein synthesis inhibitors on formation of platinum-DNA adducts and cisplatin sensitivity, Mol. Pharmacol. 57 (2000) 529-538.

[14] M.A. Keniry, C. Hollander, C.C. Benz, The effect of gossypol and 6-aminonicotinamide on tumor cell metabolism: a ${ }^{31} \mathrm{P}$-magnetic resonance spectroscopic study, Biochem. Biophys. Res. Commun. 164 (2) (1989) 947-953.

[15] R.L. Stolfi, J.R. Colofiore, L.D. Nord, J.A. Koutcher, D.S. Martin, Biochemical Modulation of tumor cell energy: regression of advamced spontaneous murine breast tumors with a 5-fluorouracil-containing drug combination, Canc. Res. 52 (1992) 4074-4081.

[16] D. Catanzaro, S. Nicolosi, V. Cocetta, M. Salvalaio, A. Pagetta, E. Ragazzi, M. Montopoli, G. Pasut, Cisplatin liposome and 6-amino nicotinamide combination to overcome drug resistance in ovarian cancer cells, Oncotarget 9 (2018) $16847-16860$.

[17] J.L. Sims, G.W. Sikorski, D.M. Catino, S.J. Berger, N.A. Berger, Poly(adenosinediphosphoribose) polymerase inhibitors stimulate unscheduled deoxyribonucleic acid synthesis in normal human lymphocytes, Biochemistry 21 (1982) 1813-1821.

[18] L.S. Dietrich, I.M. Friedland, L.A. Kaplan, Pyridine nucleotide metabolism: mechanism of action of the niacin antagonist, 6-aminonicotinamide, J. Biol. Chem. 233 (1958) 964-968.

[19] J.C. Street, A.A. Alfieri, J.A. Koutcher, Quantitation of metabolic and radiobiological effects of 6-aminonicotinamide in RIF-1 tumor cells in vitro, Canc. Res. 57 (1997) 3956-3962.

[20] K. Lange, E.R. Proft, Inhibition of the 6-Phosphogluconate Dehydrogenase in the rat kidney by 6-aminonicotinamide, Naunyn-Schmiedebergs Arch. Pharmakol. 267 (1970) 177-180.

[21] H. Kolbe, K. Keller, K. Lange, H. Herken, Metabolic Consequences of drug-induced inhibition of the pentose phosphate pathway in neuroblastoma and glioma cells, Biochem. Biophys. Res. Commun. 73 (2) (1976) 378-382.

[22] H. Herken, K. Lange, H. Kolbe, Brain disorders induced by pharmacological blockade of the pentose phosphate pathway, Biochem. Biophys. Res. Commun. 36 (1) (1969) 93-100.

[23] E. Kohler, H.J. Barrach, D. Neubert, Inhibition of NADP dependent oxidoreductases by the 6-aminonicotinamide analogue of NADP, FEBS Lett. 6 (3) (1970) 225-228.

[24] E.A. Noltman, Aldose-ketose isomerases, in: P.D. Boyer (Ed.), The Enzymes, vol. 6, Elsevier Inc, 1972, pp. 271-354.

[25] M. Marchand, U. Kooystra, R.K. Wierenga, A.M. Lambeir, J. Van Beeumen, F.R. Opperdoes, P.A. Michels, Glucosephosphate isomerase from Trypanosoma brucei. Cloning and characterization of the gene and analysis of the enzyme, Eur. J. Biochem. 184 (1989) 455-464.

[26] Expert Committee, World Health Organization Control of the Leishmaniases, WHO Technical Report Series 949, Geneva, Switzerland, (2010), pp. 1-186. Available from: http://whqlibdoc.who.int/trs/WHO_TRS_949_eng.pdf.

[27] B. Zulfigar, T.B. Shelper, V.M. Avery, Leishmaniasis drug discovery: recent progress and challenges in assay development, Drug Discov. Today (2017), https://doi.org/ 10.1016/j.drudis.2017.06.004 pii: S1359-6446(17)30005-3.

[28] L.J. Zatman, N.O. Kaplan, S.P. Colowick, M.M. Ciotti, The isolation and properties of the isonicotinic acid hydrazide analogue of diphosphopyridine nucleotide, J. Biol. Chem. 209 (1954) 467-484.

[29] J. Ghosh, P.J. Anderson, S. Chandrasekaran, M.G. Caparon, Characterization of

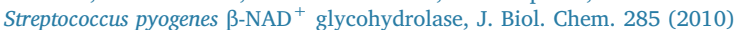
5683-5694.

[30] N.J. Oppenheimer, NAD hydrolysis: chemical and enzymatic mechanisms, Mol. Cell. Biochem. 138 (1994) 245-251.

[31] R.E. Nelson, C.P. Selitrennikoff, R.W. Siegel, Mutants of Neurospora deficient in nicotinamide adenine dinucleotide (phosphate) glycohydrolase, J. Bacteriol. 122 (1975) 695-709.

[32] J.W. Foster, A.G. Moat, Nicotinamide adenine dinucleotide biosynthesis and pyridine nucleotide cycle metabolism in microbial systems, Microbiol. Rev. 44 (1) (1980) 83-105.

[33] E. Gazanion, D. Garcia, R. Silvestre, C. Gérard, J.F. Guichou, G. Labesse, M. Seveno, A. Cordeiro-Da-Silva, A. Ouassi, D. Sereno, B. Vergnes, The Leishmania nicotinamidase is essential for $\mathrm{NAD}^{+}$production and parasite proliferation, Mol. Microbiol 82 (2011) 21-38.

[34] K.T. Hughes, B.T. Cookson, D. Ladika, B.M. Olivera, J.R. Roth, 6-aminonicotinamide-resistant mutants of Salmonella typhimurium, J. Bacteriol. 154 (1983) 1126-1136.

[35] J.R. Cobb, S.C. Pearcy, R.K. Gholson, Metabolism of 6-aminonicotinic acid in Escherichia coli, J. Bacteriol. 131 (1977) 789-794.

[36] G. Rugna, E. Carra, F. Corpus, M. Calzolari, D. Salvatore, R. Bellini, A. Di Francesco, E. Franceschini, A. Bruno, G. Poglayen, S. Varani, F. Vitale, G. Merialdi, Distinct Leishmania infantum circulate in humans and dogs in the Emilia-Romagna region, 
northeastern Italy, Vector Borne Zoonotic Dis. (March 2017), https://doi.org/10. 1089/vbz.2016.2052 ahead of print. Available from: http://online.liebertpub.com/ doi/abs/10.1089/vbz.2016.2052.

[37] R.L. Berens, R. Brun, S.M. Krassner, A simple monophasic medium for axenic cul ture of hemoflagellates, J. Parasitol. 62 (3) (1976) 360-365.

[38] P.A. Bates, C.D. Robertson, L. Tetley, G.H. Coombs, Axenic cultivation and characterization of Leishmania mexicana amastigote-like forms, Parasitology 105 (2) (1992) 193-202.

[39] Lancaster MV, Fields RD. Antibiotic and Cytotoxic Drug Susceptibility Assays Using Resazurin and Poising Agents. US Patent No. 5,501,959. 1996.

[40] Q.L. Fivelman, I.S. Adagu, D.C. Warhurst, Modified fixed-ratio isobologram method for studying in vitro interactions between atovaquone and proguanil or dihydroartemisinin against drug-resistant strains of Plasmodium falciparum, Antimicrob. Agents Chemother. 48 (11) (2004) 4097-4102.

[41] R.C. Li, J.J. Schentag, D.E. Nix, The fractional maximal effect method: a new way to characterize the effect of antibiotic combinations and other nonlinear pharmacodynamic interactions, Antimicrob. Agents Chemother. 37 (3) (1993) 523-531.

[42] F.M. Marim, T.N. Silveira, D.S. Lima Jr., D.S. Zamboni, A method for generation of bone marrow-derived macrophages from cryopreserved mouse bone marrow cells, PLoS One 5 (2010) e15263.

[43] D.J. Creek, A. Jankevics, R. Breitling, D.G. Watson, M.P. Barrett, K.E.V. Burgess, Toward global metabolomics analysis with hydrophilic interaction liquid chromatography-mass spectrometry: improved metabolite identification by retention time prediction, Anal. Chem. 83 (2011) 8703-8710.

[44] D.J. Creek, A. Jankevics, K.E.V. Burgess, R. Breitling, M.P. Barrett, IDEOM: an Excel interface for analysis of LC-MS-based metabolomics data, Bioinformatics 28 (2012) 1048-1049.

[45] M.C. Chambers, B. Maclean, R. Burke, D. Amodei, D.L. Ruderman, S. Neumann, et al., A Cross-platform toolkit for mass spectrometry and proteomics, Nat. Biotechnol. 30 (10) (2012) 918-920.

[46] J.D. Holman, D.L. Tabb, P. Mallick, Employing ProteoWizard to convert raw mass spectrometry data, Curr Protoc Bioinformatics 46 (2015) 13.24.1-13.24.9.

[47] C.A. Smith, E.J. Want, G. O'Maille, R. Abagyan, G. Siuzdak, XCMS: processing mass spectrometry data for metabolite profiling using nonlinear peak alignment, matching and identification, Anal. Chem. 78 (2006) 779-787.

[48] R. Tautenhahn, C. Boettcher, S. Neumann, Highly sensitive feature detection for high resolution LC/MS, BMC Bioinf. 9 (2008) 504.

[49] H.P. Benton, E.J. Want, T.M.D. Ebbels, Correction of mass calibration gaps in liquid chromatography-mass spectrometry metabolomics data, Bioinformatics 26 (2010) 2488.

[50] L.W. Sumner, A. Amberg, D. Barrett, M.H. Beale, R. Beger, A.C. Daykin, et al., Proposed minimum reporting standards for chemical analysis chemical analysis working group (CAWG) metabolomics standards initiative (MSI), Metabolomics 3 (3) (2007) 211-221.

[51] K. Haug, R.M. Salek, P. Conesa, J. Hastings, P. de Matos, M. Rijnbeek, T. Mahendraker, M. Williams, S. Neumann, P. Rocca-Serra, E. Maguiree, A. Gonzalez-Beltran, S.A. Sansone, J.L. Griffin, C. Steinbeck, MetaboLights - an open-access general-purpose repository for metabolomics studies and associated meta-data, Nucleic Acids Res. 41 (2013) D781-D786, https://doi.org/10.1093/nar/ gks1004 PubMed PMID: 23109552. Europe PMC: PMC3531110.

[52] M. Oz, D.E. Lorke, M. Hasan, G.A. Petroianu, Cellular and molecular actions of methylene blue in the nervous system, Med. Res. Rev. 31 (1) (2011) 93-117.

[53] G.C. Zhao, J.J. Zhu, H.Y. Chen, Spectroscopic studies of the interactive model of methylene blue with DNA by means of $\beta$-cyclodextrin, Spectrochim. Acta 55 (1999) 1109-1117.

[54] X. Hu, K. Jiao, W. Sun, J.Y. You, Electrochemical and spectroscopic studies on the interaction of malachite green with DNA and its application, Electroanalysis 6 (2006) 613-620.

[55] F. Ding, X.N. Li, J.X. Diao, Y. Sun, L. Zhang, L. Ma, X.L. Yang, L. Zhang, Y. Sun, Potential toxicity and affinity of triphenylmethane dye malachite green to lysozyme, Ecotoxicol. Environ. Saf. 78 (2012) 41-49.

[56] M. Bertelli, E. El-Bastawissy, M.H. Knaggs, M.P. Barrett, S. Hanau, I.H. Gilbert, Selective inhibition of 6-phosphogluconate dehydrogenase from Trypanosoma brucei, J. Comput. Aided Mol. Des. 15 (2001) 465-475.

[57] L. Tretter, G. Horvath, A. Holgyesi, F. Essek, V. Adam-Vizi, Enhanced hydrogen peroxide generation accompanies the beneficial bioenergetic effects of methylene blue in isolated brain mitochondria, Free Radic. Biol. Med. 77 (2014) 317-330.

[58] E. Poteet, A. Winters, L.J. Yan, K. Shufelt, K.N. Green, J.W. Simpkins, Y. Wen,
S.H. Yang, Neuroprotective actions of methylene blue and its derivatives, PLoS One 7 (10) (2012) e48279.

[59] T. Tsuchiya, A. Matuoka, S. Sekita, T. Hisano, A. Takahashi, MJr Ishidate, Human embryonic cell growth assay for teratogens with or without metabolic activation system using microplate, Teratog. Carcinog. Mutagen. 8 (1988) 265-272.

[60] T.G. Geary, A.A. Divo, J.B. Jensen, Nutritional requirements of Plasmodium falciparum in culture. II. Effects of antimetabolites in a semi-defined medium, J. Protozool. 32 (1985) 65-69.

[61] D. Sereno, A. Monte Alegre, R. Silvestre, B. Vergnes, A. Ouaissi, In vitro antileishmanial activity of nicotinamide, Antimicrob. Agents Chemother. 49 (2) (2005) 808-812.

[62] D. Sereno, B. Vergnes, F. Mathieu-Daude, A. Cordeiro da Silva, A. Ouaissi, Looking for putative functions of the Leishmania cytosolic SIR2 deacetylase, Parasitol. Res. 100 (2006) 1-9.

[63] M. Ouaissi, A.J. Ouaissi, Histone deacetylase enzymes as potential drug targets in cancer and parasitic diseases, J. Biomed. Biotechnol. (2006) 13474, , https://doi. org/10.1155/JBB/2006/13474 1-10.

[64] N.S. Carter, P.A. Yates, S.K. Gessford, S.R. Galagan, S.M. Landfear, B. Ullman, Adaptive responces to purine starvation in Leishmania donovani, Mol. Microbiol. 78 (2010) 92-107.

[65] J. Xia, I.V. Sinelnikov, B. Han, D.S. Wishart, MetaboAnalyst 3.0 - making metabolomics more meaningful, Nucleic Acids Res. 43 (2015) W251-W257, https://doi. org/10.1093/nar/gkv380.

[66] A. Carmona, R.A. Freedland, Effect of 6-aminonicotinamide on pentose cycle activity in isolated hepatocytes, Int. J. Biochem. 22 (1990) 595-599.

[67] J. Kovarova, A.W. Pountain, D. Wildridge, S. Weidt, F. Bringaud, R.J.S. Burchmore, F. Achcar, M.P. Barrett, Deletion of transketolase triggers a stringentmetabolic response in promastigotes and loss of virulence in amastigotes of Leishmania mexicana, PLoS Pathog. 14 (3) (2018) e1006953.

[68] P.O.J. Ogbunude, N. Lamour, P. Barrett, Molecular cloning, expression and characterization of ribokinase of Leishmania major, Acta Biochimica Biophysica (Sinica) 39 (2007) 462-466.

[69] S. Gatreddi, S. Are, I.A. Qureshi, Ribokinase from Leishmania donovani: Purification, Characterization and X-ray Crystallographic Analysis, (2018), pp. 99-104 F74.

[70] P.A.M. Michels, L. Avilan, The NAD + metabolism of Leishmania, notably the enzyme nicotinamidase involved in $\mathrm{NAD}^{+}$salvage, offers prospects for development of anti-parasite chemotherapy, Mol. Microbiol. 82 (2011) 4-8.

[71] N.S. Carter, P.A. Yates, C.S. Arendt, J.M. Boitz, B. Ullman, Purine and pyrimidine metabolism in Leishmania, Adv. Exp. Med. Biol. 625 (2008) 141-154.

[72] J.C. Whitney, D. Quentin, S. Sawai, M. Le Roux, B.N. Harding, H.E. Ledvina, B.Q. Tran, H. Robinson, D.R. Goodlett, S. Raunser, J.D. Mougous, An Interbacterial $\mathrm{NAD}(\mathrm{P})+$ glycohydrolase toxin requires Elongation Factor Tu for delivery to target cells, Cell 163 (2015) 607-619.

[73] R.H. Glew, A.K. Saha, S. Das, A.T. Remaley, Biochemistry of the Leishmania species, Microbiol. Rev. 52 (1988) 412-432.

[74] J.M. Boitz, B. Ullman, Adenine and adenosine salvage in Leishmania donovani, Mol. Biochem. Parasitol. 190 (2013) 51-55.

[75] G.D. Westrop, R.A. Williams, L. Wang, T. Zhang, D.G. Watson, A.M. Silva, G.H. Coombs, Metabolomic analyses of Leishmania reveal multiple species differences and large differences in amino acid metabolism, PLoS One 10 (9) (2015) e0136891https://doi.org/10.1371/journal.pone.0136891.

[76] S. Hanau, K. Montin, I.H. Gilbert, M.P. Barrett, F. Dallocchio, Inhibitors of Trypanosoma brucei 6-phosphogluconate dehydrogenase, Curr. Bioact. Compd. 3 (2007) 161-169.

[77] S. Hanau, L. Proietti d'Empaire, I. Capone, S. Alberighi, R. Montioli, F. Dallocchio, Evidence for dimer/tetramer equilibrium in Trypanosoma brucei 6-phosphogluconate dehydrogenase, Biochim. Biophys. Acta 1834 (12) (2013) 2647-2652.

[78] C. Dardonville, E. Rinaldi, M.P. Barrett, R. Brun, I.H. Gilbert, S. Hanau, Selective inhibition of Trypanosoma brucei 6-phosphogluconate dehydrogenase by high energy intermediate and transition state analogues, J. Med. Chem. 47 (2004) 3427-3437.

[79] G.F. Ruda, P.E. Wong, V.P. Alibu, S. Norval, K.D. Read, M.P. Barrett, I.H. Gilbert, Aryl phosphoramidates of 5-phospho erythronohydroxamic acid, a new class of potent trypanocidal compounds, J. Med. Chem. 53 (16) (2010) 6071-6078. Aug 26.

[80] D. Gonzalez, J.L. Perez, M.L. Serrano, M. Igoillo-Esteve, J.J. Cazzulo, M.P. Barrett, J. Bubis, A. Mendoza-Leon, The 6-phosphogluconate dehydrogenase of Leishmania (Leishmania) mexicana: gene characterization and protein structure prediction, J. Mol. Microbiol. Biotechnol. 19 (2010) 213-223. 